Article

\title{
The Internal Structure of Yellow Cuboid Diamonds from Alluvial Placers of the Northeastern Siberian Platform
}

\author{
Alexey Ragozin ${ }^{1,2, *}$ (D), Dmitry Zedgenizov ${ }^{1,2}$, Konstantin Kuper ${ }^{3}$, Viktoria Kalinina ${ }^{1,2}$ \\ and Alexey Zemnukhov ${ }^{4}$ \\ 1 V. S. Sobolev Institute of Geology and Mineralogy, Siberian Branch Russian Academy of Sciences, \\ Novosibirsk 630090, Russia; zed@igm.nsc.ru (D.Z.); vika@igm.nsc.ru (V.K.) \\ 2 Department of Geology and Geophysics, Novosibirsk State University, Novosibirsk 630090, Russia \\ 3 Budker Institute of Nuclear Physics, Siberian Branch Russian Academy of Sciences, Novosibirsk 630090, \\ Russia; k.e.kuper@inp.nsk.su \\ 4 JSC Almazy Anabara, Yakutsk 678174, Russia; zemnuchoval@alanab.ru \\ * Correspondence: ragoz@igm.nsc.ru; Tel.: +7-383-330-8015
}

Academic Editors: Yuri N. Palyanov

Received: 30 June 2017; Accepted: 28 July 2017; Published: 31 July 2017

\begin{abstract}
Yellow cuboid diamonds are commonly found in diamondiferous alluvial placers of the Northeastern Siberian platform. The internal structure of these diamonds have been studied by optical microscopy, X-Ray topography (XRT) and electron backscatter diffraction (EBSD) techniques. Most of these crystals have typical resorption features and do not preserve primary growth morphology. The resorption leads to an evolution from an originally cubic shape to a rounded tetrahexahedroid. Specific fibrous or columnar internal structure of yellow cuboid diamonds has been revealed. Most of them are strongly deformed. Misorientations of the crystal lattice, found in the samples, may be caused by strains from their fibrous growth or/and post-growth plastic deformation.
\end{abstract}

Keywords: diamond; internal structure; electron backscatter diffraction; X-ray topography

\section{Introduction}

Diamond crystals develop diverse morphological and physical properties, which reflect the variation of conditions during diamond formation which largely occurs in the upper mantle [1-9]. Morphology and internal structure of natural diamond crystals reflect the conditions of growth and following post-growth history. The study of mineral inclusion in diamonds and xenoliths of diamondiferous rocks in kimberlites show that diamonds can be crystallized in various upper mantle rocks: peridotites (olivine, orthopyroxene, garnet, and diopside), eclogites (garnet, clinopyroxene) and, rarely, websterites [10-12]. P-T models propose that most diamonds are formed in the diamond's stability field, in temperature ranges $\left(900-1300{ }^{\circ} \mathrm{C}\right)$ and pressures $(4.5-6 \mathrm{GPa})$ that correspond to the depth of formation (140-200 km) [13].

The Siberian platform hosts more than one thousand known kimberlite pipes. Numerous $(>100)$ kimberlite pipes have been discovered within the northeastern part of the Siberian platform, most are barren or very poorly diamondiferous [14]. Despite the very low diamond-bearing capacity of kimberlite pipes in this region, approximately $70 \%$ of the diamond alluvial placer deposits of the Siberian platform are located here [15]. The primary sources of the diamonds in these placers have not been discovered yet.

The alluvial deposits of the Northeastern Siberian platform have specific diamond association [16,17]. Previous studies have revealed several diamond populations, which may be 
related with various primary sources [18,19]. Under the Orlov classification [5], these diamonds can be classified into three groups: (1) typical octahedral and rounded dodecahedral diamonds of variety I; (2) yellow-orange or dark grey cuboids of varieties II and III; and (3) rounded dark crystals of variety V.

Diamonds with cubic crystals (cuboids), forming an incessant colour gradient from yellowish-green to yellow and dark orange, are widespread in alluvial placers of the Northeastern Siberian platform. These diamonds have been categorized as variety II in the mineralogical classification [5]. Diamonds of this variety constitute approximately $7-7.5 \%$ of the alluvial placer diamond collection [15]. Diamond crystals of cubic habit are infrequent in Siberian kimberlites and they are no greater in number than $2 \%$ of the total diamonds found in the region. Thus, it is unlikely that the kimberlites discovered in the Siberian platform are the source of these diamond placers. In some other regions, e.g., Mbuji-Mayi (Congo), Ekati (Canada), and Jwaneng (Botswana), many cuboid diamonds are found in the kimberlites $[8,20,21]$. The characteristics of variety II diamonds, i.e., specific morphological features, the low values of $\delta^{13} \mathrm{C}$ and high levels of nitrogen in the C-form (single substitutional nitrogen impurity, type $\mathrm{Ib}$-causing yellow coloration), testify to their unusual primary source $[19,22]$. This study investigates the specific features related to the internal structures of these cuboid diamonds and is part of an extensive study of alluvial diamonds from the Northeastern Siberian platform [23-30].

\section{Results}

\subsection{Morphological Features}

An infrequent pattern of natural diamond formation is the cube, which is a rough approximation of the ideal form [31]. Figures 1 and 2 are microphotograph and SEM images of the most typical variety II diamonds from alluvial placers of the Northeastern Siberian platform. These cuboid diamonds are almost cubic or sub-rounded crystals; most studied diamonds are isometric but, in some cases, the crystals are more or less distorted (flattened or elongated at three- or four-fold axes) (Figures 1 and 2). The diamonds of interest in this study are yellow (all diamonds in this study belong to rare type $\mathrm{Ib}$ ) and some are turbid yellow due to micro-inclusions. Studied diamonds have typical dissolution features, e.g., patterns of numerous few stepped, pyramidal etch pits of rectangular shape on their (100) planes (Figure 2e,f) and rounded surfaces that correspond to tetrahexahedroid corners at cubic edges. There are no crystals with sharp cube edges; all samples have epigenetic dissolution. Rectangular-etched pits on the cubic faces of diamonds are known as tetragons. Tetragonal pits lie on each of the (100) surfaces; each pit is turned around at an angle of $45^{\circ}$ with regard to the form of the cubic facets. It was found that convex crystals are usually covered with faces at the maximum speed of dissolution, whereas concave bodies tend to be faceted at a minimal velocity [32]. Rounded convex surfaces produce rounded habits in some crystals with characteristic morphological tetrahexahedroid features of (Figure 2c,h). Experimental data shows that diamond crystals transform their habits during dissolution from cubes to tetrahexahedroids in water-containing systems, when the weight loss is $>50 \%$ [33]. The surface textures of studied crystals include fine striation along $<110>$ on (100) faces and many elongated hillocks on the rounded convex surfaces of tetrahexahedroid (Figure 2f). Some rounded surfaces of studied crystals contain etched holes (Figure 2c) and/or channels (Figure 2a), which frequently occur at visible cracks extending through the crystals volumes. The relics of cubic faces of studied crystals are not perfectly flat and diverge from precise crystallographic planes (100), i.e., becoming convex or concave. 

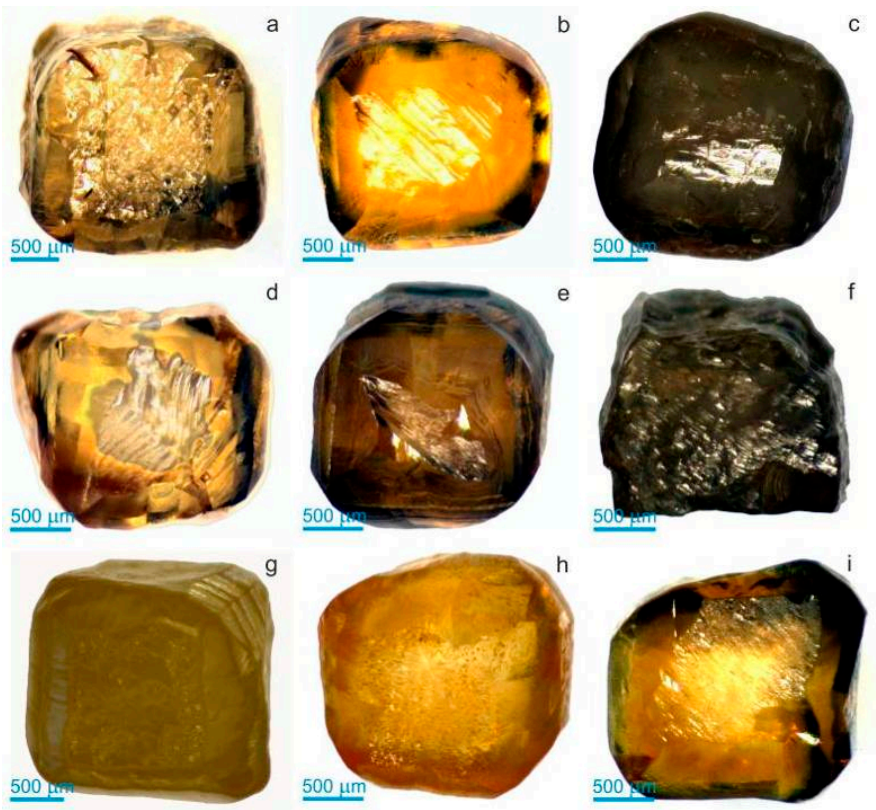

Figure 1. Optical microphotographs of cuboid diamonds from the Northeastern Siberian platform (a-Light yellow crystal MP-30 of predominant cubic habit; b-Orange-yellow crystal MP-43 of combination form (cube-tetrahexahedroid); c-Yellowish-grey diamond rounded crystal MP-56; d-Light yellow crystal MP-30 of transition form (cube-tetrahexahedroid); e-Dark yellow crystal MP-60 of combinational form (cube-tetrahexahedroid); f-Yellowish-grey diamond crystal MP-83 of cubic habit; g-Greyish-yellow crystal MP-87 of combination form (cube-tetrahexahedroid); h-Yellow crystal MP-98 of transition form (cube-tetrahexahedroid); i-Orange-yellow crystal MP-43 of combination form (cube-tetrahexahedroid)).
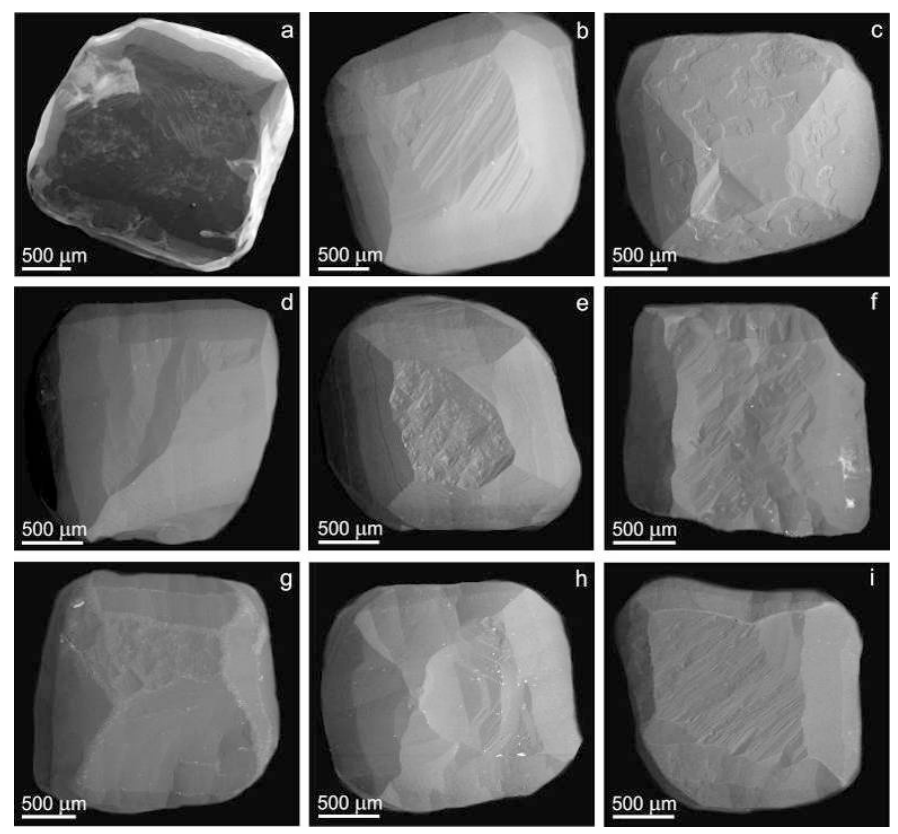

Figure 2. SEM micrographs showing morphological features of cuboid diamonds from the Northeastern Siberian platform (a-The crystal MP-30 of predominant cubic habit with small rounded tetrahexahedroid surfaces of at the cube edges; $\mathbf{b}-$ The crystal MP-43 of combinational form (cube-tetrahexahedroid) with fine striation along $<110>$ on (100) faces; c-The diamond crystal 
MP-56 of predominantly tetrahexahedroid habit with cube faces which are almost totally replaced by the rounded surfaces, there are only relics of (100) faces with large $(\sim 400 \mu \mathrm{m})$ negative tetragonal etch pits of rectangular shape and numerous shallow micro-pits with elliptical or irregularly curved outlines (corrosion sculptures) on rounded teraxehedroid surfaces; $\mathbf{d}$-The crystal MP-60 of transitional form (cube-tetrahedroid); e-The crystal MP-71 of combinational form (cube-tetrahexahedroid), relics of cube face have numerous stepped, flat-bottomed, and pyramidal etch pits of rectangular shape, there are concentric terraces on the rounded surfaces. $\mathbf{f}$-The diamond crystal MP-83 of cubic habit with tetragonal etch pits and fine striation along $<110>$; g-The crystal MP-87 of combinational form having flat cubic faces with tetragonal pyramidal etch pits and rounded surfaces of tetrahexahedroid, there are blunted and rounded edges and apices which correspond with intense mechanical abrasion; $\mathbf{h}-$ The crystal MP-98 of transitional form (cube-tetrahedroid); i-The crystal MP-108 of combinational form (cube-tetrahexahedroid) with fine striations along $<110>$ on the (100) faces).

\subsection{Internal Structure}

\subsubsection{Optical Microscopy}

The nine diamonds were polished to consist of plates parallel to a crystallographic (110) plane with a $200-400 \mu \mathrm{m}$ thickness. The observations of polished plates by optical microscopy showed that cuboid diamonds have inhomogeneous internal structures. All diamonds showed concentrical zonation having growth zones with different intensity of colouration (Figure 3). Intensively-coloured zones are regularly sited in the centre of crystals. On the other hand, in some cases (Figure 3d) the centre of the crystals are colourless, while the outer zone is intensely yellow. Moreover, there are more sophisticated patterns with heterogeneous spreading of growth zones with dissimilar coloration (Figure $3 b, c, e, i, h)$. Several crystals showed growth zones with multiple micro-inclusions spreading as a chain along the (111) direction (Figures $3 a, f$ and $4 a, b$ ). Such patterns are typical for diamonds of cubic habit and may reflect their fibrous internal structure [25].

In fact a birefringence interference pattern is not supposed for crystals of cubic symmetry which includes diamonds; its appearance suggest strong deformation of the diamond's crystal structure [4,34-37]. In other words, irregular birefringence reflects an accidental imperfection of the crystal structure. The straining of the crystal structure may result from (1) dislocations; (2) lattice parameter deviations (caused by lattice impurities); (3) physical impurities (mineral and fluid inclusions; (4) cracks; and (5) plastic deformation [36]. The fibrous internal structure of diamonds with cubic habits, which consist of sub-parallel fibres diverging in lines from a common centre (crystals core), has been previously recognized by X-ray topography [31,38]. The misorientations between subindividuals (fibres) in studied diamonds produce a deformation of crystals, which results in the patterns of anomalous birefringence (Figure 5). The interference of highest degree is detected at the boundaries between various growth zones and/or sectors (Figure 5a,e,f). The crystal samples exhibit zonal and sectorial birefringence patterns. They often have brindled interference patterns, and in some parts of the crystals patterns include thin lines intersecting each other in different $<111>$ directions. The latter is called "tatami" pattern and explained by the influence of post-growth plastic deformations by the dislocation gliding mechanism [39]. 


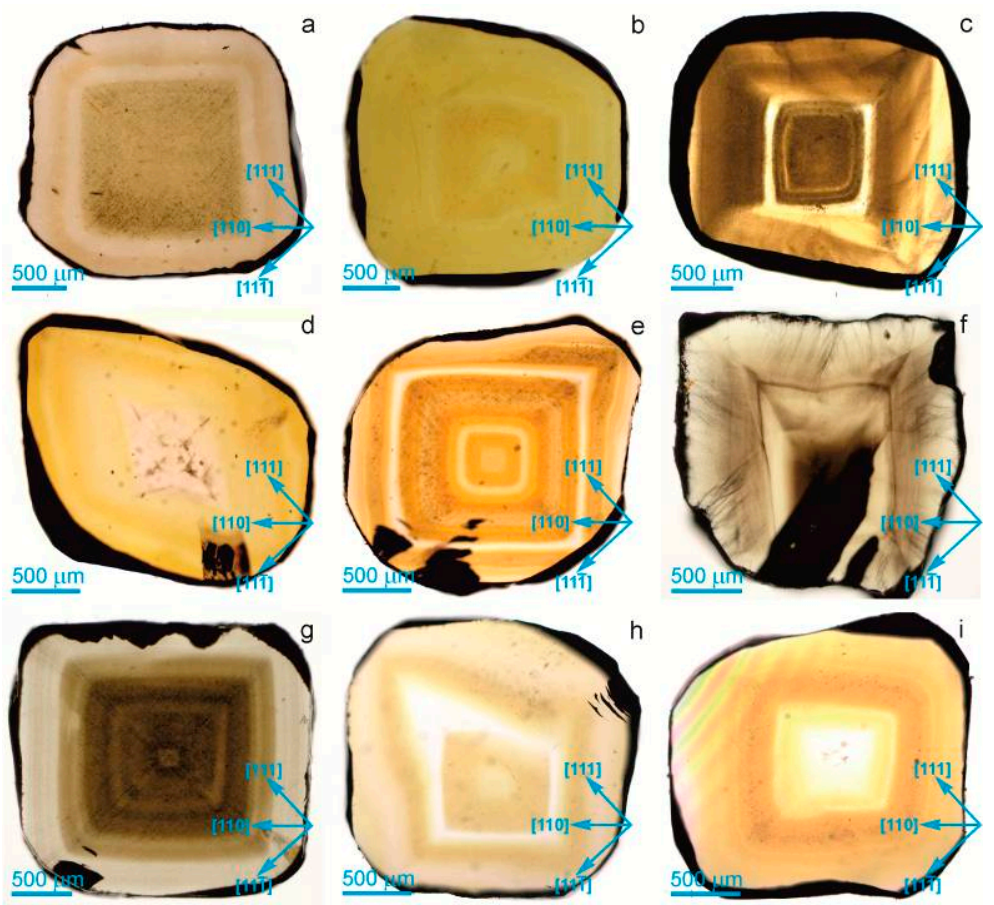

Figure 3. Internal structure of yellow cuboid diamonds from the Northeastern Siberian platform (optical microphotographs of double-polished plates parallel to (110), transmitted polarized light) (a-The crystal MP-30 having zonal structure, cube-shaped core with microinclusions located by chains that defined radial distribution; $\mathbf{b}$ - The diamond MP-43 having cubic zones of slightly different intensities of yellow coloration; c-The crystal MP-56 with zonal distribution of numerous microinclusions, there are inclusion-free zones and zones with different densities of microinclusions; $\mathbf{d}$-The crystal MP-60 having light yellow inner core and intense yellow outer zones; e-The diamond MP-71 having numerous cubic zones with different intensity of yellow coloration; $\mathbf{f}-$ The diamond MP-83 with clear zonal and sectorial texture; there are radial chains of microinclusions in outer zones; $\mathrm{g}$-The crystal MP-87 having zonal structure having muddy yellow core zone with high microinclusion density and an inclusion-free rim. In core there are several zones with different inclusions density; $\mathbf{h}-\mathrm{The}$ diamond having distorted cubic zones with different intensities of yellow colour; $i$-The diamond having colourless inner core and numerous cubic zones with different intensity of yellow colour in outer rim).
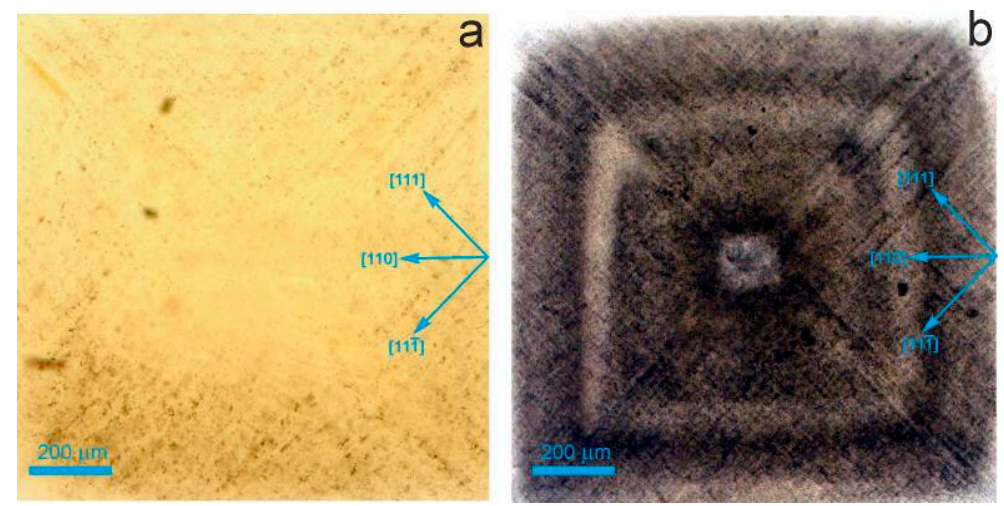

Figure 4. Core regions of diamonds (a-M-30, $\mathbf{b}-\mathrm{MP}-87)$ with abundant microinclusions. 

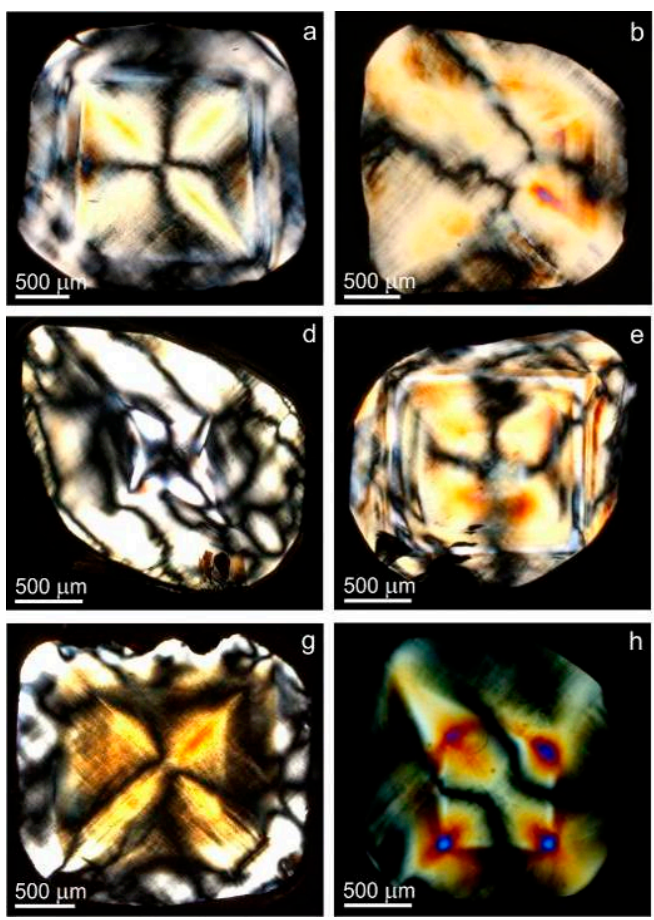
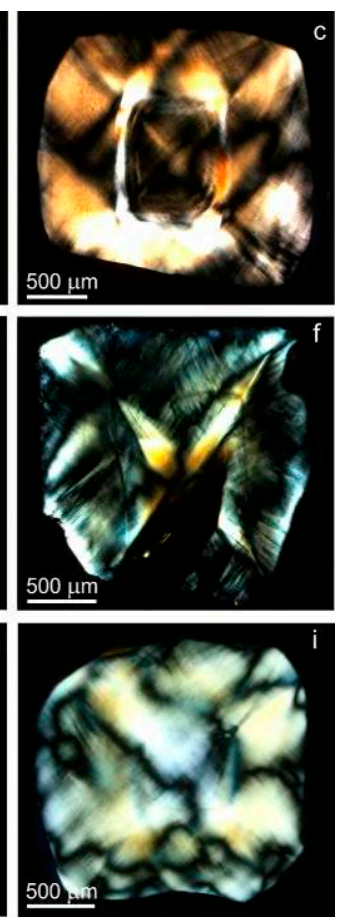

Figure 5. Anomalous birefringence patterns of double-polished plates of yellow cuboid diamonds from the Northeastern Siberian platform (photos taken between crossed polarizers) (a-MP-30; b-MP-43; c-MP-56; d-MP-60; e-MP-71; f-MP-83; g-MP-87; h-MP-98; i-MP-108).

\subsubsection{X-ray Topography (XRT)}

Figure 6 shows $X$-ray projection topography images of the cuboid diamond samples. These diamonds normally display a diffraction contrast due to dislocations [40-42]. The topographical structures (Figure $6 b, c, g$ ) are like those found in $[31,32,38]$. The crystal structures found in the XRT study can be characterized as "fibrous" or "columnar" [31]. This is due to the subdivision of the crystal (monocrystalline) volume into slightly mutually misorientated subindividuals (columns), the axial directions of which were $<111>$. The column's diameter ranged from about $10 \mu \mathrm{m}$ downwards to the resolution limits of the technique (approx. $1 \mu \mathrm{m}$ ). The X-ray topographs show that the development of the volume of the growing crystal is associated with repeated branching in the equivalent $<111>$ directions. Therefore, this data shows that cuboid diamonds of variety II have been crystallized by fibrous growth in the $<111>$ direction with branching and equal velocities in the equivalent directions. In some X-ray topographs, clear sectorial and zoning structures of the crystals were observed (Figure 6a,c-e). Zoning structures visible on X-ray topographs are due to deformation of the crystal lattice (probably caused by lattice impurities) between growth zones, which often have different colouring in transmitted light (see Figure 3). 

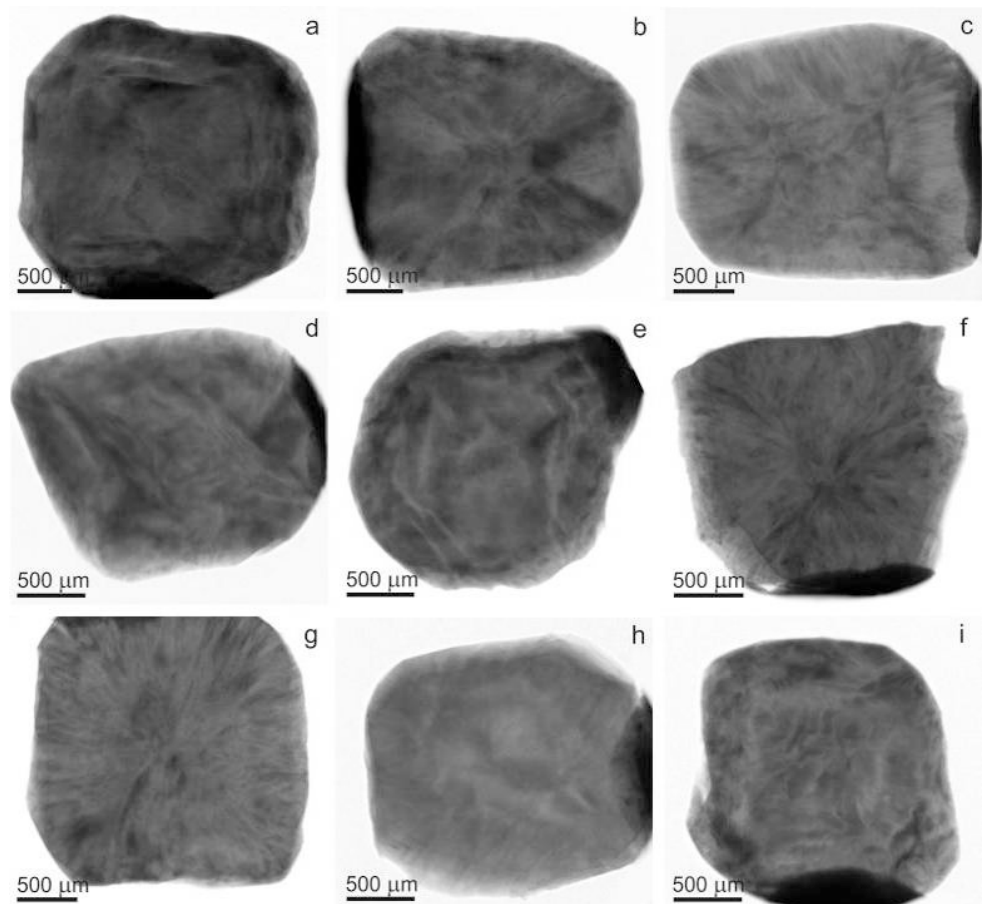

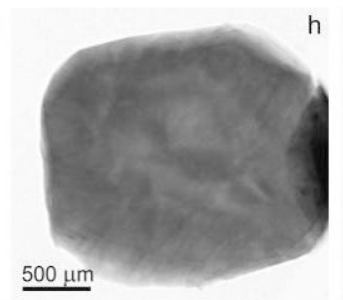

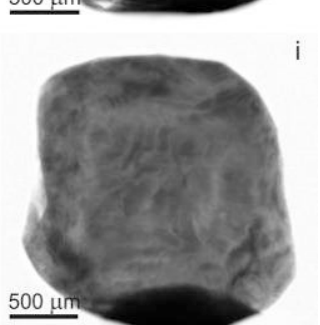

Figure 6. X-ray projection topographs of yellow cuboid diamonds from the Northeastern Siberian platform (the Burgers vector is directed horizontally to the left, (220) reflection) (a-MP-30; b-MP-43; c-MP-56; d-MP-60; e-MP-71; f-MP-83; g-MP-87; h-MP-98; i-MP-108).

\subsubsection{Electron Backscatter Diffraction (EBSD)}

The electron backscatter diffraction (EBSD) technique allows accurate identification of the structural characters of crystals, manifested as lattice orientation relationships between the columns or as a deformation lamination. The EBSD images (Figure 7) show that the diamond samples consist of domains, which are misoriented to each other. Blue to red coloration on the images correspond to misorientations of up to $2^{\circ}$. The higher misorientations have been observed in the outer parts of the various growth sectors of the cuboids. These patterns support the suggestion that fibrous growth of sample cuboid diamonds are the repeated branching of fibres in equivalent $<111>$ directions. This branching causes the stronger strains of the outer crystal zones. Some diamonds exhibit strain patterns expressed as a lamination in two crossed directions (Figure $7 \mathrm{~d}, \mathrm{e}, \mathrm{h}$ ). These patterns, as in birefringence, could be attributed to post-growth plastic deformations. 


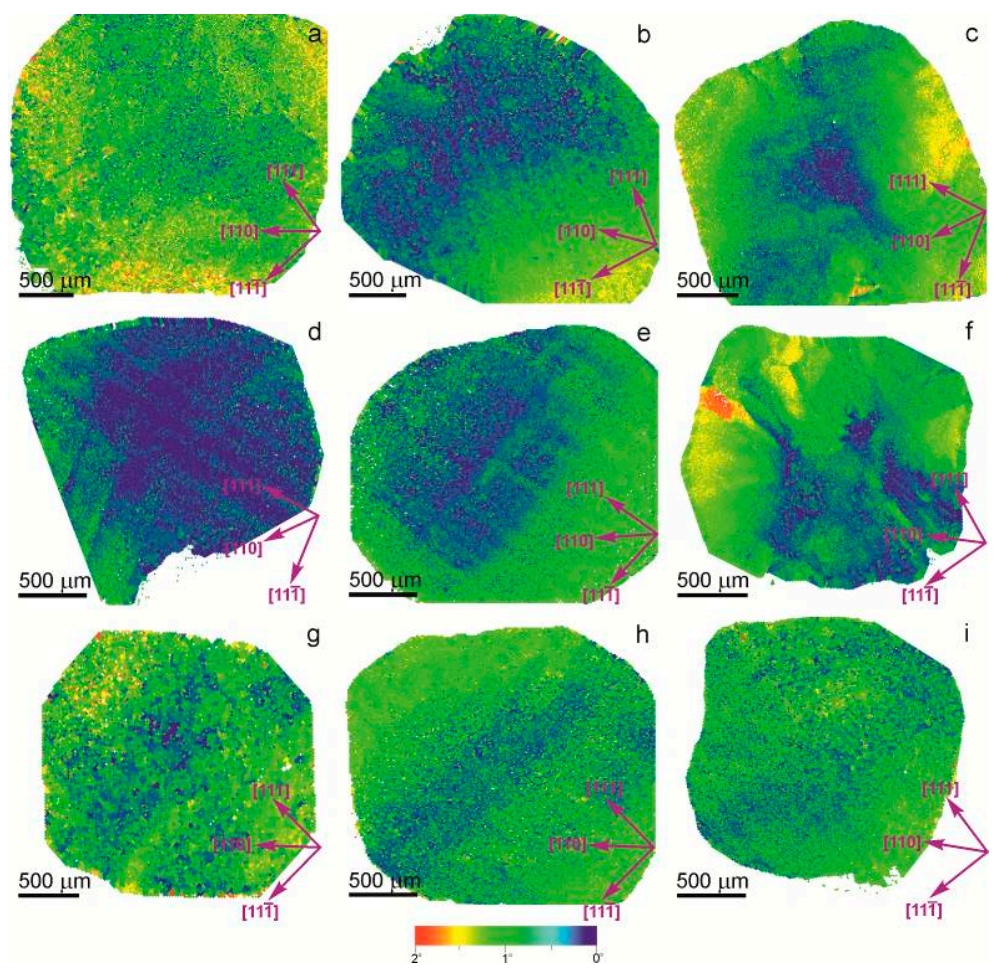

Figure 7. Misorientation patterns of yellow cuboid diamonds from the Northeastern Siberian platform. EBSD maps over a large parts of the polished plates showing a change in orientation up to $2^{\circ}$ from blue to red (a-MP-30; b-MP-43; c-MP-56; d-MP-60; e-MP-71; f-MP-83; g-MP-87; h-MP-98; i-MP-108).

\section{Discussion}

Previous studies $[30,39]$ of yellow cuboid diamonds from alluvial placers of the Northeastern Siberian platform revealed the overall presence of $C$ centres (single substitution-based nitrogen defects). The presence of these centres is usually attributed either to relatively cool conditions of the storage of diamonds in the mantle or short mantle residence time prior to eruption. These cuboid diamonds show a wide range of carbon isotope compositions, from mantle-like values towards lighter values [30]. Mineral inclusions found in these diamonds testify to their formation in eclogitic environments, which is believed to correspond to deeply-subducted protoliths of the former oceanic crust.

The morphology of diamonds may be caused by the different physical and chemical conditions of growth and post-growth alteration. The morphological features of diamonds often reflect only the last stages of their evolution, connected with resorption and/or regeneration. Observed rounded morphology of most yellow cuboid diamonds indicates their post-growth resorption, rather than represents primary growth morphologies. The resorption of cuboid diamond typically result in transformation into rounded dodecahedral morphology through gradual inflation of crystal surfaces. These morphological features are generally similar to those observed in partially resorbed diamond crystals of cubic habit in experiments [33,43].

It was shown that cuboid diamonds have fibrous internal structure $[31,32,38,44]$. The X-ray topography studies demonstrate that fibres represent less than $20 \mu \mathrm{m}$ sub-individuals oriented along the equivalent $<111>$ directions direction. Growth of diamonds with such internal structures are not accompanied by a thickening of these sub-individuals. Splitting the fibres in the equivalent equivalent $<111>$ directions directions led to total space filling of the cuboid sectors [31]. The growth mechanism is reflected in the X-ray topography and EBSD images. 
According to [44], cuboid diamonds with specific fibrous internal structures could be crystallized under high supersaturation. Fibrous internal structures of diamonds likely resulted from fast abnormal growth at high carbon supersaturation operating as a driving force of this process. This concept has additionally been proposed by theoretical models [45]. The fibrous internal structure identified in the studied cuboid diamonds can also be described by the position of the abnormal growth.

Cuboid diamond crystals may have suffered post-growth annealing and plastic deformation. The plastic deformation of the diamond samples are reflected in internal structure features. These structures appear as a "tatami" pattern (two crossed directions of strain lamination) in EBSD images and birefringence patterns. Moreover, the deformation of a crystal lattice in the sample diamonds also took place during the fibrous or columnar crystal growth. The rounded shape, negative etch pits, and other dissolution features of studied samples are suggested to be the result of resorption. The resorption has resulted in a gradual transformation of crystals with nearly cubic shape into rounded tetrahexahedrons (tetrahexahedroid) [33].

\section{Methods}

The cuboid diamonds were first examined with optical microscopy using a Zeiss Stemi SV 6 stereo microscope (Carl Zeiss Microscopy GmbH, Göttingen, Germany). The morphology of the crystals has been studied using a scanning electron microscope (JEOL JSM-6510LV (20 kV), Japanese Electron Optics Laboratory Ltd., Tokyo, Japan) installed in the Analytical Centre for Multi-Element and Isotope Research SB RAS, Novosibirsk, Russia.

The internal structure of crystals has been visualized through the method of $\mathrm{X}$-ray projection topography (XRT). The X-ray topograms were obtained over the whole samples synchronously translated with the detector under the beam $[42,46]$. The images were collected from superposition of the section images in the Bragg reflection geometry. The spatial resolution of the detector with a factor of 20 has been increased using a mirror magnification system. A double-crystal Si monochromator was tuned to the (333) reflection to avoid the influence of the high-energy harmonics.

The misorientations of the crystal structure in cuboid diamonds was determined from the EBSD mapping of polished plates [47]. The EBSD data were collected on a Hitachi S-3400 N scanning electron microscope equipped with an Oxford Instruments HKL detector with an accuracy of misorientations of $0.5-1.0^{\circ}$ (Oxford Instruments plc, Abingdon, UK). The Kikuchi pattern of each individual point were automatically indexed by the Oxford data collection software. Patterns were acquired on rectangular grids by moving the electron beam at a regular step size of $1 \mu \mathrm{m}$.

The XRT and EBSD study was performed using the infrastructure of the Shared-Use Centre at the Siberian Synchrotron and Terahertz Radiation Centre (SSTRC) based on the VEPP-3/VEPP-4M/NovoFEL at the Budker Institute of Nuclear Physics SB RAS, Novosibirsk, Russia.

\section{Conclusions}

The internal structure of yellow cuboid diamonds found in alluvial placers of the Northeastern Siberian platform have been investigated via optical microscopy, XRT, and EBSD techniques. We have demonstrated that these cuboid diamonds have a specific fibrous or columnar internal structure. Most are strongly deformed and have a brindled internal structure. Misorientations of the crystal lattice, found in the samples, may be caused by strains from their fibrous growth or/and post-growth plastic deformation. Most of the crystals have typical resorption features and do not preserve primary growth morphology. The resorption leads to an evolution from an originally cubic shape to a rounded tetrahexahedroid. 
Acknowledgments: The research was supported by state assignment project (project no. 0330-2016-0007).

Author Contributions: Alexey Ragozin studied samples by scanning electron microscopy and analysed the data; Dmitry Zedgenizov studied samples by optical microscopy and analysed the data; Viktoria Kalinina made the polished plates from diamonds and discussed the results; Konstantin Kuper performed the electron backscatter diffraction and X-ray topography experiments; Alexey Zemnukhov analysed the data and discussed the results; and Alexey Ragozin and Dmitry Zedgenizov contributed equally by writing the manuscript.

Conflicts of Interest: The authors declare no conflict of interest.

\section{References}

1. Harrison, E.R.; Tolansky, S. Growth history of a natural octahedral diamond. Proc. R. Soc. Lond. A 1964, 279, 490-496. [CrossRef]

2. Suzuki, S.; Lang, A.R. Occurrences of facetted re-entrants on rounded growth surfaces of natural diamonds. J. Cryst. Growth 1976, 34, 29-37. [CrossRef]

3. Lang, A.R. Glimpses into the growth history of natural diamonds. J. Cryst. Growth 1974, 24, $108-115$. [CrossRef]

4. Varshavsky, A.V. Anomalous Birefringence and Internal Morphology of Diamond; Nauka: Moscow, Russia, 1968; p. 92. (In Russian)

5. Orlov, Y.L. The Mineralogy of Diamond; John Wiley: New York, NY, USA, 1977; p. 233.

6. Gurney, J.J.; Helmstaedt, H.H.; Richardson, S.H.; Shirey, S.B. Diamonds through time. Econ. Geol. 2010, 105, 689-712. [CrossRef]

7. Harris, J.W. Diamond geology. In The Properties of Natural and Synthetic Diamond; Field, J.E., Ed.; Academic Press: London, UK, 1992; pp. 345-393.

8. Welbourn, C.M.; Rooney, M.-L.T.; Evans, D.J.F. A study of diamonds of cube and cube-related shape from the jwaneng mine. J. Cryst. Growth 1989, 94, 229-252. [CrossRef]

9. Howell, D.; Griffin, W.L.; Piazolo, S.; Say, J.M.; Stern, R.A.; Stachel, T.; Nasdala, L.; Rabeau, J.R.; Pearson, N.J.; O'Reilly, S.Y. A spectroscopic and carbon-isotope study of mixed-habit diamonds: Impurity characteristics and growth environment. Am. Miner. 2013, 98, 66-77. [CrossRef]

10. Sobolev, N.V. Deep Seated Inclusions in Kimberlites and the Problem of the Composition of the Upper Mantle; AGU: Washington, DC, USA, 1977; p. 279.

11. Meyer, H.O.A. Genesis of diamond-A mantle saga. Am. Miner. 1985, 70, 344-355.

12. Meyer, H.O.A. Inclusions in diamond. In Mantle Xenoliths; Nixon, P.H., Ed.; Wiley: New York, NY, USA, 1987; pp. 501-522.

13. Stachel, T.; Harris, J.W. The origin of cratonic diamonds-Constraints from mineral inclusions. Ore Geol. Rev. 2008, 34, 5-32. [CrossRef]

14. Parfenov, L.M.; Kuzmin, M.I. Tectonics, Geodynamics and Metallogeny of the Territory of the Republic of Sakha (Yakutia); Nauka/Interperiodika: Moscow, Russia, 2001; p. 571. (In Russian)

15. Grakhanov, S.A.; Shatalov, V.I.; Shtyrov, V.A.; Kychkin, V.R.; Suleimanov, A.M. Diamond Placers of Russia; Akademicheskoe Izd.“Geo”: Novosibirsk, Russia, 2007; p. 454. (In Russian)

16. Zinchuk, N.N.; Koptil, V.I. Typomorphism of Diamonds in the Siberian Craton; Nedra: Moscow, Russia, 2003; p. 603. (In Russian)

17. Zinchuk, N.N.; Koptil, V.I.; Boris, E.I.; Lipashova, A.N. Typomorphic features of placer diamonds from the Siberian craton: A principle guide in diamond exploration. Rudy Met. 1999, 3, 18-30.

18. Afanas'ev, V.P.; Zinchuk, N.N.; Koptil, V.I. Polygenesis of diamonds in connection with the problem of northeastern primary sources of Siberian platform. Dokl. Akad. Nauk 1998, 361, 366-369.

19. Afanas'ev, V.P.; Lobanov, S.S.; Pokhilenko, N.P.; Koptil', V.I.; Mityukhin, S.I.; Gerasimchuk, A.V.; Pomazanskii, B.S.; Gorev, N.I. Polygenesis of diamonds in the Siberian platform. Russ. Geol. Geophys. 2011, 52, 259-274. [CrossRef]

20. Gurney, J.J.; Hildebrand, P.R.; Carlson, J.A.; Fedortchouk, Y.; Dyck, D.R. The morphological characteristics of diamonds from the Ekati property, Northwest Territories, Canada. Lithos 2004, 77, 21-38. [CrossRef]

21. Posukhova, T.; Kolume, F. Diamonds from placers in Western and Central Africa: A problem of primary sources. Mosc. Univ. Geol. Bull. 2009, 64, 177-186. [CrossRef] 
22. Galimov, E. The relation between formation conditions and variations in isotope composition of diamonds. Geochem. Int. 1985, 22, 118-141.

23. Shatsky, V.S.; Zedgenizov, D.A.; Ragozin, A.L.; Kalinina, V.V. Diamondiferous subcontinental lithospheric mantle of the northeastern siberian craton: Evidence from mineral inclusions in alluvial diamonds. Gondwana Res. 2015, 28, 106-120. [CrossRef]

24. Shatsky, V.S.; Zedgenizov, D.A.; Ragozin, A.L.; Kalinina, V.V. Carbon isotopes and nitrogen contents in placer diamonds from the ne siberian craton: Implications for diamond origins. Eur. J. Miner. 2014, 26, 41-52. [CrossRef]

25. Zedgenizov, D.A.; Ragozin, A.L.; Shatsky, V.S.; Araujo, D.; Griffin, W.L. Fibrous diamonds from the placers of the northeastern Siberian platform: Carbonate and silicate crystallization media. Russ. Geol. Geophys. 2011, 52, 1298-1309. [CrossRef]

26. Zedgenizov, D.; Rubatto, D.; Shatsky, V.; Ragozin, A.; Kalinina, V. Eclogitic diamonds from variable crustal protoliths in the northeastern siberian craton: Trace elements and coupled $\delta^{13} \mathrm{C}-\delta^{18} \mathrm{O}$ signatures in diamonds and garnet inclusions. Chem. Geol. 2016, 422, 46-59. [CrossRef]

27. Ragozin, A.L.; Zedgenizov, D.A.; Kuper, K.E.; Shatsky, V.S. Radial mosaic internal structure of rounded diamond crystals from alluvial placers of Siberian platform. Miner. Petrol. 2016, 110, 861-875. [CrossRef]

28. Ragozin, A.L.; Shatskii, V.S.; Zedgenizov, D.A. New data on the growth environment of diamonds of the variety V from placers of the northeastern Siberian platform. Dokl. Earth Sci. 2009, 425, 436. [CrossRef]

29. Ragozin, A.L.; Shatsky, V.S.; Rylov, G.M.; Goryainov, S.V. Coesite inclusions in rounded diamonds from placers of the northeastern Siberian platform. Dokl. Earth Sci. 2002, 384, 385-389.

30. Zedgenizov, D.A.; Kalinina, V.V.; Reutsky, V.N.; Yuryeva, O.P.; Rakhmanova, M.I. Regular cuboid diamonds from placers on the northeastern Siberian platform. Lithos 2016, 265, 125-137. [CrossRef]

31. Lang, A.R. Space-filling by branching columnar single-crystal growth: An example from crystallisation of diamond. J. Cryst. Growth 1974, 23, 151-153. [CrossRef]

32. Orlov, Y.L.; Bulienkov, N.A.; Martovitsky, V.P. A study of the internal structure of variety III diamonds by X-ray section topography. Phys. Chem. Miner. 1982, 8, 105-111. [CrossRef]

33. Khokhryakov, A.F.; Pal'yanov, Y.N. The evolution of diamond morphology in the process of dissolution: Experimental data. Am. Miner. 2007, 92, 909-917. [CrossRef]

34. Howell, D. Strain-induced birefringence in natural diamond: A review. Eur. J. Miner. 2012, 24, 575-585. [CrossRef]

35. Howell, D.; Piazolo, S.; Dobson, D.; Wood, I.; Jones, A.; Walte, N.; Frost, D.; Fisher, D.; Griffin, W. Quantitative characterization of plastic deformation of single diamond crystals: A high pressure high temperature (HPHT) experimental deformation study combined with electron backscatter diffraction (EBSD). Diam. Relat. Mater. 2012, 30, 20-30. [CrossRef]

36. Lang, A.R. Causes of birefringence in diamond. Nature 1967, 213, 248-251. [CrossRef]

37. Tolansky, S. Birefringence of diamond. Nature 1966, 211, 158-160. [CrossRef]

38. Moore, M.; Lang, A.R. On the internal structure of natural diamonds of cubic habit. Philos. Mag. 1972, 26, 1313-1325. [CrossRef]

39. Titkov, S.V.; Shiryaev, A.A.; Zudina, N.N.; Zudin, N.G.; Solodova, Y.P. Defects in cubic diamonds from the placers in the northeastern Siberian platform: Results of ir microspectrometry. Russ. Geol. Geophys. 2015, 56, 354-362. [CrossRef]

40. Authier, A. Contrast of images in X-Ray topography. In Diffraction and Imaging Techniques in Materials Science; Amelinckx, S., Gevers, R., Van Landuyt, J., Eds.; North-Holland: Amsterdam, The Netherlands, 1978; Volume 2, pp. 715-757.

41. Lang, A.R. Techiques and interpretation in X-ray topography. In Diffraction and Imaging Techniques in Materials Science; Amelinckx, S., Gevers, R., Van Landuyt, J., Eds.; North-Holland: Amsterdam, The Netherlands, 1978; Volume 2, pp. 623-714.

42. Lang, A.R. The projection topograph: A new method in X-ray diffraction microradiography. Acta Crystallogr. 1959, 12, 249-250. [CrossRef]

43. Khokhryakov, A.F.; Pal'yanov, Y.N. Evolution of diamond morphology in the processes of mantle dissolution. Lithos 2004, 73, S57.

44. Sunagawa, I. Growth and morphology of diamond crystals under stable and metastable contitions. J. Cryst. Growth 1990, 99, 1156-1161. [CrossRef] 
45. Chernov, A.A. Stability of faceted shapes. J. Cryst. Growth 1974, 24-25, 11-31. [CrossRef]

46. Kuper, K.E.; Zedgenizov, D.A.; Ragozin, A.L.; Shatsky, V.S. X-ray topography of natural diamonds on the VEPP-3 SR beam. Nucl. Insrum. Meth. A 2009, 603, 170-173. [CrossRef]

47. Humphreys, F.J. Review grain and subgrain characterisation by electron backscatter diffraction. J. Mater. Sci. 2001, 36, 3833-3854. [CrossRef] 